\title{
ANALISIS SISTEM INFORMASI WEB LSP UAD MENGGUNAKAN USER EXPERIENCE QUESTIONNAIRE (UEQ)
}

\author{
Rusydi Umar, Aulyah Zakilah Ifani ${ }^{\bowtie}$, Fathia Irbati Ammatulloh, Maya Anggriani \\ Magister Teknik Informatika, Universitas Ahmad Dahlan, Yogyakarta, Indonesia \\ Email: aulyah1908048022@webmail.uad.ac.id
}

DOI: https://doi.org/10.46880/jmika.Vol4No2.pp173-178

\begin{abstract}
The progress of the world has been so fast that workers in various professions have increasingly needed recognition. University and Vocational School graduates need fields to test the ability of the profession they do. Ahmad Dahlan University (UAD) is one of the universities that has a professional testing institution called the UAD Professional Certification Institute (LSP). LSP UAD functions as an institution to test the professions required by prospective UAD graduates themselves. Until now, LSP UAD has ten schemes that can be tested on prospective study program graduates. To simplify the information related to the scheme, students can see on the LSP UAD website, information is also available for other LSPs and accessories. However, the UAD LSP web has not tested the satisfaction of web users such as student users. This paper was created to test user satisfaction or User Experience (UX) for users to improve information services on the web. Analysis on the UAD LSP web used the User Experience Questionnaire (UEQ) method to 15 students who had used the web as respondents. $U E Q$ 's assessment refers to six aspects, namely: efficiency, attractiveness, accuracy, clarity, novelty, and stimulation. The results of the analysis showed that the average respondent gave an impression with results above average in the aspects of clarity, accuracy, stimulation, and novelty. Meanwhile, attractiveness and efficiency get good scores.
\end{abstract}

Keyword: Information System, UEQ, User Experience, LSP UAD.

\begin{abstract}
ABSTRAK
Kemajuan dunia sudah sangat pesat hingga para pekerja berbagai profesi sudah semakin membutuhkan pengakuan. Para lulusan Universitas maupun Sekolah Kejuruan membutuhkan ladang untuk menguji kemampuan profesi yang digelutinya. Universitas Ahmad Dahlan (UAD) salah satu perguruan tinggi yang memiliki sebuah lembaga uji profesi bernama Lembaga Sertifikasi Profesi (LSP) UAD. LSP UAD berfungsi sebagai lembaga untuk menguji profesi yang dibutuhkan oleh calon lulusan UAD itu sendiri. Hingga kini LSP UAD mempunyai sepuluh skema yang dapat diujikan kepada calon lulusan prodi. Untuk mempermudah informasi terkait skema tersebut mahasiswa dapat melihat di web LSP UAD, tersedia juga informasi untuk para asesordan LSP lain. Namun, web LSP UAD belum melakukan uji kepuasanpengguna web tersebut seperti pengguna mahasiswa. Paper ini dibuat untuk menguji kepuasan pengguna atau User Experience (UX) kepada para pengguna untuk meningkatkan kembali layanan informasi yang terdapat di web. Analisis pada web LSP UAD menggunakan metode User Experience Questionnare (UEQ) kepada 15 mahasiswa yang telah menggunakan web tersebut sebagai responden. Penilaian UEQ mengacu pada enam aspek yaitu: efisiensi, daya tarik, ketepatan, kejelasan, kebaruan, dan stimulasi. Hasil analisis didapatkan bahwa rata-rata responden memberikan impresi dengan hasil diatas rata-rata pada aspek kejelasan, ketepatan, stimulasi, dan kebaruan. Sedangkan daya tarik dan efisiensi mendapatkan nilai baik.
\end{abstract}

Kata Kunci: Sistem Informasi, UEQ, Pengalaman Pengguna, LSP UAD.

\section{PENDAHULUAN}

Sistem informasi dalam sebuah lembaga ataupun sebuah institusi pendidikan memiliki peran yang sangat penting. Sistem informasi menjadi komponen utama karena merupakan dasar dalam menyediakan informasi. Sistem informasi merupakan sebuah sistem dalam suatu organisasi yang memiliki sifat manajerial (Septa \& Umar, 2019). Sistem informasi digunakan dalam menyediakan informasi manajemen (Umar, Sarjimin, Nugroho, Dito, \& Gunawan, 2020). Sistem informasi juga dapat digunakan sebagai kebutuhan dalam peningkat pelayanan (Umar, Siswanto, et al., 2020). Selain itu juga sistem informasi menjadi penentuan mutu dari sebuah 
lembaga atau dari sebuah perguruan tinggi. LSP UAD menjadi salah satu lembaga yang menggunakan atau menerapkan sistem informasi akademik pada Universitas Ahmad Dahlan. Web LSP UAD digunakan oleh beberapa pengguna salah satunya yaitu mahasiswa.

LSP UAD bertujuan sebagai wadah untuk mahasiswa melakukan uji kompetensi sesuai kompetensinya. Uji kompetensi merupakan syarat kelulusan dari Universitas Ahmad Dahlan, dimana merupakan peningkatan mutu lulusan UAD. Uji kompetensi tersebut terdiri beberapa skema yaitu skema sertifikasi kepala cabang/manager koperasi jasa keuangan, skema sertifikasi programmble logic controller (PLC), skema sertifikasi pendamping komunitas, skema sertifikasi database administrator, skema sertifikasi ahli higiene industri muda, skema sertifikasi keselamtan dan kesehatan kerja muda, skema sertifikasi pengujian laboratorium. Web LSP UAD ditinjau dari pengguna mahasiswa belum pernah dilakukan uji experience. Segala informasi berkaitan dengan kegiatan uji kompetensi terdapat pada Web LSP UAD. User Experience Questionnaire (UEQ) dicobakan Agar mahasiswa lebih mudah dalam mengakses web LSP UAD (Halim, Handoko, \& Marpaung, 2020).

User Experience Questionnaire (UEQ) digunakan untuk menghitung evaluasi User Experience (UX) (Fitranda, Az-zahra, \& Herlambang, 2019). Membangun User Experience dalam sebuah prinsip penilaian menentukan tingkat kepuasan sendiri dalam penilaian User Experience berupa kepuasan, kenyamanan akan sebuah jasa, produk, dll. Dengan melalukan penilaian User Experience dapat diketahui apa yang dialami pengguna, kemudahan, dan rasa puas ketika menggunakan web (Widhiani, Arthana, \& Pradnyana, 2018).

User experience memiliki enam skala pengukuran yaitu Attractiveness, efficiency, perspiculty, dependability, stimulation, dan novelty (Wulandari \& Farida, 2018). Attractiveness (daya tarik) terkait bagaimana kesan pertama seseorang terhadap sebuah produk. Effeciency (efisiensi) terkait seberapa besar pengguna menyelesaikan tugasnya dengan cepat serta efisien. Perspiculty (kejelasan) terkait dengan apakah pengguna dapat menyelesaikan tugasnya dengan mudah. Dependability (ketepatan) berkaitan dengan seberapa besar ketepatan pengguna dapat melakukan interaksi ketika menggunakan produk lebih aman. Stimulation (stimulasi) berkaitan dengan seberapa besar pengguna ketika menggunakan produk merasa termotivasi. Novelty (kebaruan) berkaitan dengan apakah prodek yang digunakan kreatif atau tidak kreatif (Halim et al., 2020). Pengukuran User Experience Web LSP UAD dengan UEQ dilakukan untuk mengetahui level experience pada Web LSP UAD dengan kuesioner oleh 15 responden pengguna Web LSP UAD mahasiswa Universitas Ahmad Dahlan Yogyakarta (Fitranda et al., 2019).

Penelitian ini menganalisa User Experience melalui User Experience Questionnaire (UEQ) pada Web LSP AD untuk dapat mengukur pengalaman pengguna pada saat menggunakan sistem.

\section{KAJIAN LITERATUR}

Para peneliti telah banyak meneliti tentang penggunaan User Experience Questionnaire (UEQ) dalam mendukung pendekatan pada pengalaman pengguna. Salah satu penelitian yang dilakukan Izabal, dkk., tentang Evaluasi dan Perbaikan User Experience Menggunakan User Experience Questionnaire (UEQ) dan Focus Group Discussion (FGD) pada Situs Web FILKOM Apps Mahasiswa Fakultas Ilmu Komputer Universitas Brawijaya. Hasil penelitian ini mengatakan skala persepsi memiliki peningkatan persepsi positif terbesar, kemudian efficiency dan attractiveness (Izabal, Aknuranda, \& Az-zahra, 2018).

Penelitian lainnya yang dilakukan oleh Adinegoro, dkk., mengenai Analisis Pengalaman Pengguna pada Website E-commerce dengan Menggunakan Usability Testing dan User Experience Questionnaire (UEQ) dengan studi kasus pada Lazada.co.id, Blibli.com dan JD.id. Hasil skenario dari tiga studi kasus tersebut menunjukan hasil positif dalam kuesioner UEQ (Adinegoro, Rokhmawati, \& Az-Zahra, 2018). Sedangkan Wulandari \& Farida telah melakukan penelitian mengenai Pengukuran User Experience Pada E-Learning di Lingkungan Universitas Menggunakan User Experience Questionnaire (UEQ). Hasil penelitian menunjukan level below Average pada skala daya tarik (attractiveness) sebesar 0,87, kejelasan (perspiculty) sebesar 0,85, efisiensi (effeciency) sebesar 0,89, ketepatan (dependability) sebesar 0,84, dan stimulasi (stimulation) sebesar 0,84 menunjukan bahwa ke 5 skala tersebut berada pada level below avarage, sedangkan skala kebaruan (novelty) berada pada level bad sebesar 0,29 (Wulandari \& Farida, 2018).

Pada penelitian lainnya Suastini, Lanang, \& Satwika telah meneliti tentang Analisis Pengalaman Pengguna Website Pada Website Distro Management System (Dimans). Hasil menunjukan pada penelitian subjektif responden memberikan impresi yang cenderung positif dengan nilai rata- rata yang 
mencapai impresi sangat baik (excellent) (Suastini, Lanang, \& Satwika, 2018). Sedangkan Febrianto, dkk., telah meneliti tentang Analisis Pengalaman Pengguna Aplikasi Sistem Informasi Puskesmas Paperless Menggunakan Metode Usability Testing dan User Experience Questionnaire (UEQ). Penelitian dilakukan terhadap 25 orang responden yang menghasilkan aspek nilai rata- rata 1,137 yang memiliki arti pengguna aplikasi Simple cenderung memberikan penilaian kearah positif (Febrianto, Putra, \& Perdanakusuma, 2019).

\section{METODE PENELITIAN}

Penelitian ini menganalisa pengalaman mahasiswa dalam menggunakan WEB LSP UAD melalui uji User Experience. Metode analisis digunakan dan penyebaran kuesioner User Experience Questionnaire (UEQ) baik secara langsung maupun menggunakan media google form kepada mahasiswa Universitas Ahmad Dahlan yang pernah mengakses website WEB LSP UAD. Aspek penelitian terdiri dari 6 aspek yaitu attractiveness, efficiency, perspicuity, dependability, dependability dan novelty.

Metode UEQ digunakan pada penelitian ini sebagai acuan untuk mengukur tingkat kepuasan pengguna web LSP UAD. Analisis yang didapat pada penelitian ini nantinya berupa data kuantitatif deskriptif untuk mengetahui tingkat kepuasan pengguna yaitu mahasiswa UAD. Hasil dari beberapa penelitian menggunakan UEQ mendapatkan nilai validitas yang baik. Poin UEQ memiliki istilah yang berlawanan dam skala satu sampai tujuh menjadi rentang skala pada setiap poin. Lingkaran - lingkaran yang berada diantara dua kata menjadi acuan penilaian yang bertolak belakang. Responden dapat memilih salah satu dari lingkaran tersebut yang paling dekat dengan kesan yang ingin disampaikan.

\section{menyusahkan $\bigcirc \quad 0 \quad 0 \quad \bullet \quad 0 \quad 0$ menyenangkan}

Gambar 1. Contoh Pengisian UEQ

Gambar diatas menunjukan bahwa responden menilai lebih menyenangkan dibanding menyusahkan. UEQ telah diterjemahkan ke dalam 20 bahasa, gambar 2 berikut ini adalah versi Bahasa Indonesia.

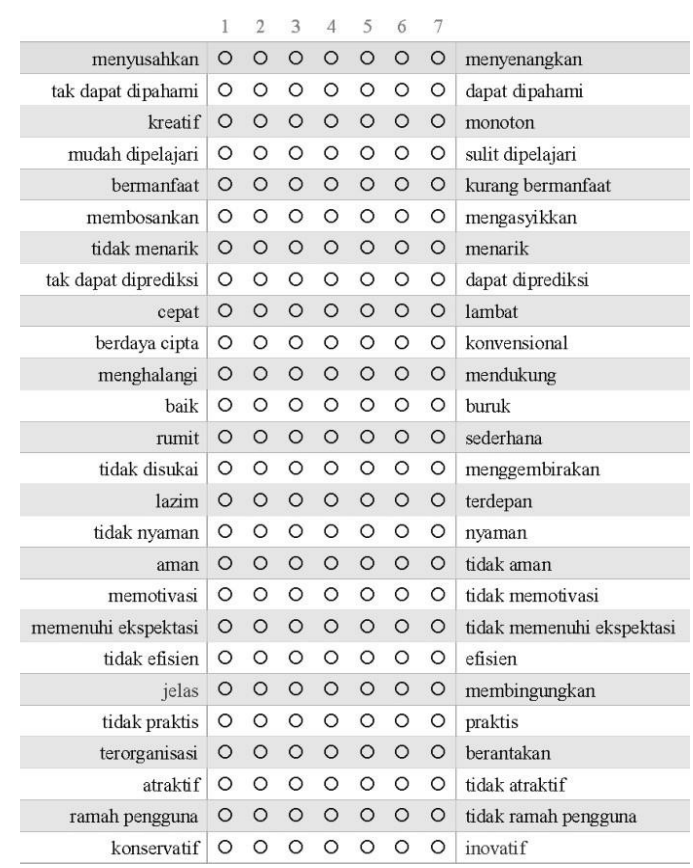

Gambar 2. UEQ Versi Bahasa Indonesia

Gambar 2 diatas menunjukkan aspek penilaian $U E Q$ dalam versi bahasa indonesia. Menghitung ratarata setiap aspek dilakukan untuk mendapatkan hasil analisis UEQ. Point-poin pertanyaan memiliki nilai acak positif maupun negative. Setiap aspek memiliki setengah nilai positif dan setengah nilai negative skala 1 sampai 7 ke rentang nilai -3 sampai dengan +3 .

Aspek penilaian per poin memiliki nilai antara +1 sampai dengan +2 , maka sudah menunjukan penilaian dengan kualitas yang sangat baik karena responden jarang memberikan nilai paling maksimum dan minimum. Penilaian standar pada UEQ di nilai antara -0.8 bernilai negatif dan +0.8 positif. Selain pengujian UEQ, uji brenchmark juga perlu dengan melakukan perbandingan setiap nilai aspek dengan data UEQ yang ada pada UEQ analysis data tool. Hasil uji brenchmark terbagi menjadi 5 kategori didalamnya terdapat Bad, Average, Below, Above Average, Good, dan Excellent. Nilai untuk setiap kategori dapat dilihat pada Tabel 1.

Tabel 1. Kategori Pada UEQ Data Analysis Tool

\begin{tabular}{|l|l|c|c|c|c|c|}
\hline \multirow{2}{*}{ No } & \multirow{2}{*}{ Aspek } & $\begin{array}{c}\text { Excelle } \\
\boldsymbol{n t}\end{array}$ & Good & $\begin{array}{c}\text { Above } \\
\text { Average }\end{array}$ & $\begin{array}{c}\text { Below } \\
\text { Average }\end{array}$ & Bad \\
\hline 1 & Daya Tarik & $>1.75$ & $>1.52$ & $>1.17$ & $>0.7$ & $<=0.7$ \\
\hline 2 & Kejelasan & $>1.9$ & $>1.56$ & $>1.08$ & $>0.64$ & $<=0.64$ \\
\hline 3 & Efisiensi & $>1.78$ & $>1.47$ & $>0.98$ & $>0.54$ & $<=0.54$ \\
\hline 4 & Ketepatan & $>1.65$ & $>1.48$ & $>1.14$ & $>0.78$ & $<=0.78$ \\
\hline 5 & Stimulasi & $>1.55$ & $>1.31$ & $>0.99$ & $>0.5$ & $<=0.3$ \\
\hline 6 & Kebaruan & $>1.4$ & $>1.05$ & $>0.71$ & $>0.3$ & $<=0.5$ \\
\hline
\end{tabular}


Interpretasi pada setiap kategori adalah:

1) Excellent: skor tertiggi produk kisaran $10 \%$,

2) Good: $10 \%$ produk skor yang lebih tinggi, sedangkan $50 \%$ lebih rendah,

3) Above Average: $25 \%$ produk dataset lebih tingi, $50 \%$ lebih rendah,

4) Below Average: $50 \%$ produk dataset lebih tinggi, $25 \%$ lebih rendah,

5) Bad: $25 \%$ memiliki skor rendah

Hasil analisa data UEQ menggunakan data tools UEQ dalam format .xlsx (Microsoft Excel). Data yang didapat dari hasil kuesioner dapat langsung dimasukan pada data tools UEQ pada menu Data, peneliti memasukan data responden ke dalam menu Data. Data tools UEQ memiliki beberapa tahapan, yaitu:

1) Konversi Data (Data Transformed)

Data responden yang telah dimasukan ke excel akan mengalami proses konversi data yaitu urutan nilai (positif kanan dan negatif kiri) diacak dalam kuesioner untuk meminimalkan kecenderungan jawaban. Seperti pada gambar 3 berikut ini:

\begin{tabular}{|c|}
\hline Konversi Data \\
\hline $1 \rightarrow-3$ \\
\hline $2 \rightarrow-2$ \\
\hline $3 \rightarrow-1$ \\
\hline $4 \rightarrow 0$ \\
\hline $5 \rightarrow 1$ \\
\hline $6 \rightarrow 2$ \\
\hline $7 \rightarrow 3$ \\
\hline
\end{tabular}

Gambar 3. Konversi Data

Gambar 3 menunjukkan proses urutan nilai yang digunakan untuk meminimalkan kecenderungan jawaban dari setiap penelian. Data yang dikonversi akan menghasilkan nilai rata-rata perorang dengan masing-masing pengelompokkan berdasarkan aspek. Berikut rumus dari konversi data:

$$
\bar{x}=\frac{\sum \bar{x}[\text { person }]}{\sum \text { item }} \ldots \ldots \ldots \ldots(i)
$$

Keterangan:

$\bar{x}=$ rataan skala perorang

$\sum \bar{x}[$ person $]=$ total item perskala
$\sum$ item $=$ jumlah item per skala
2) Hasil utama

Setelah dikonversikan data dihitung kembali untuk mendapatkan hasil utama yaitu Result. Result adalah hasil utama dari UEQ yang menjadi tolak ukur untuk perhitungan selanjutnya yaitu benchmark. Skala keseluruhan dan skala asumsi dihitung menggunakan nilai rata-rata dan varian daria hasil rata-rata konversi data. Penentuan hasil rata-rata skala memiliki nilai standar yaitu -0.8 dan 0.8 merupakan hasil normal, nilai $>0.8$ merupakan nilai positif dan nilai negatif.

Perhitungan result:

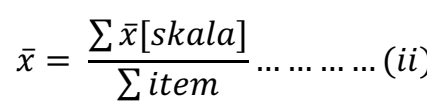

Keterangan:

$\bar{x}=$ rataan skala perorang

$\sum \bar{x}[$ skala $]=$ total item per skala
$\sum$ item $=$ total responden

3) Set Data Benchmark

UEQ menggunakan standar benchmark, dengan data 246 evaluasi dan responden 9905 perhitungan ini digunakan untuk perbandingan kualitas dengan data 246. Hasil rata-rata dan analisa result digunakan untuk mendapatkan nilai perbandingan. Nilai standar benchmark yaitu: Excellent: hasil mean >1.75, Good: hasil mean >1.2, Above Average: hasil mean $>1.17$, Below Average: hasil mean $>0.7$, dan Bad: hasil mean $<0.7$.

\section{HASIL DAN PEMBAHASAN}

Analisis Sistem Informasi dilakukan kepada 100 mahasiswa yang merupakan responden yang sudah pernah menggunakan web LSP UAD. Dengan jumlah pertanyaan 26 yang meliputi 6 aspek setiap poin memiliki nilai 1 sampai 7 .

Setiap jawaban kemudian dikonversikan secara berurutan seperti pada Gambar 3. Konversi Data. Sehingga dihasilkan seperti pada Gambar 4. Mean, Varian, dan Simpangan Baku. 


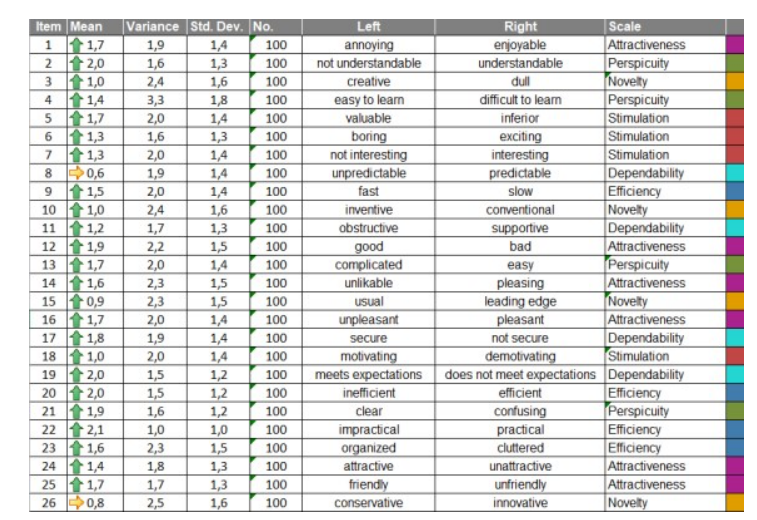

Gambar 4. Mean, Varian, Simpangan Baku

Gambar 4 menunjukan hasil mean, varian, simpang baku setelah dilakukan konversi data. Masing-masing pertanyaan diberi warna yang sama dengan aspeknya dan telah dihitung nilai varian, simpangan baku, dan meannya. Hasilnya dapat dilihat pada Gambar 5. Rata-rata Impresi.

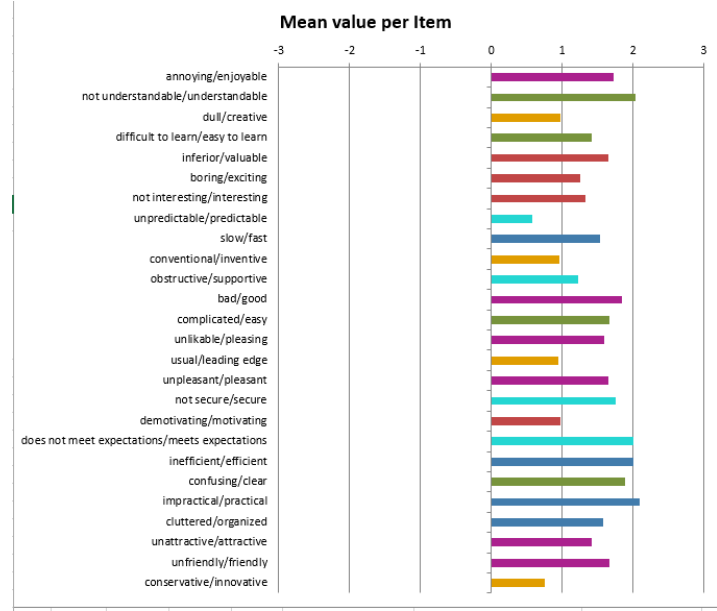

Gambar 5. Rata-rata Impresi

Gambar 5 menunjukan rata-rata impresi yang didapatkan setelah dilakukan penghitungan nilai mean, varian dan simpang baku. Nilai rata-rata dari setiap pertanyaan dapat dilihat pada Gambar 6 .

\begin{tabular}{|l|r|r|}
\hline \multicolumn{3}{|c|}{ UEQ Scales (Mean and Variance) } \\
\hline Attractiveness & 1,652 & 1,42 \\
\hline Perspicuity & 1,748 & 1,22 \\
\hline Efficiency & 1,803 & 0,93 \\
\hline Dependability & 1,803 & 0,69 \\
\hline Stimulation & 1,390 & 1,14 \\
\hline Novelty & iि 1,303 & 1,20 \\
\hline
\end{tabular}

Gambar 6. Rata-rata Impresi dan Varian Skala.

Gambar 6 menunjukkan rata-rata impresi dan varian skala. Nilai rata-rata dari keseluruhan pertanyaan dapat dilihat pada Gambar 7. Grafik Ratarata Impresi Skala. Hasil nilai rata-rata semua aspek termasuk ke impresi skala positif namun, nilai ratarata dari aspek kebaruan skalanya masih kurang dari aspek lain. Maka, perlu ditingkatkan dari segi pengalaman pengguna perlu ditingkatkan agar dapat mengimbangi skala pada aspek yang lain. Hasil ratarata impresi skala dapat dilihat pada Gambar 7. Grafik Rata-rata Impresi Skala.

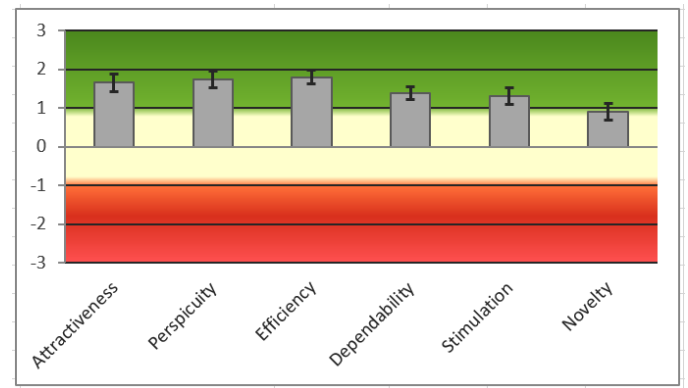

Gambar 7. Grafik rata-rata Impresi Skala

Gambar 7 menunjukkan grafik nilai rata-rata per kelompok mempunyai nilai antara -0.8 dan 0.8 yang merupakan nilai evaluasi normal, nilai $>0.8$ merupakan evaluasi positif dan nilai $<-0.8$ merupakan evaluasi negatif. Kesimpulan yang didapatkan dari grafik pada analisis web LSP UAD cenderung memiliki impresi positif dimana nilai lebih dari satu dan seterusnya dalam aspek daya Tarik, kejelasan, efisiensi, ketepatan, dan stimulasi. Sedangkan aspek kebaruan memiliki nilai impresi hampir dibawah 1. Grafik dapat dilihat pada Gambar 8. Standar Set Data Benchmark.

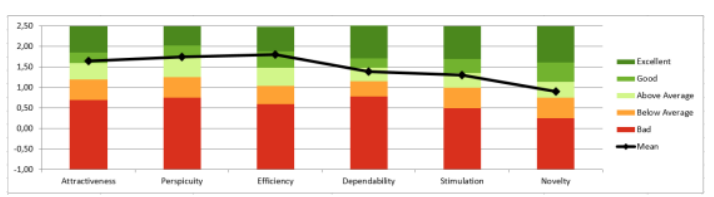

Gambar 8. Standar Set Benchmark

Gambar 8 menunjukkan standar set benchmark dimana ada skala daya Tarik nilai rata-rata 1.65. kemudian skala kejelasan mendapat nilai ratarata 1.75. Skala efisiensi mendapat nilai rata-rata 1.80 . Skala ketepatan mendapat nilai 1.80. Selanjutnya skala stimulasi mendapat nilai rata-rata 1.30 dan 0.91 skala kebaruan. Perbandingan produk analisis web dengan 246 produk dari set data benchmark dapat membantu hasil analisa untuk menentukan set data benchmark. Hasil perbandingan set data benchmark dapat dilihat pada gambar berikut:

\begin{tabular}{|l|l|l|l|}
\hline Scale & Mean & Compainson to benchimark & Interpretation \\
\hline Attractiveness & 1,65 & Good & $10 \%$ of results better, $75 \%$ of results worse \\
\hline Perspicuity & 1,75 & Above Average & $10 \%$ of results better, $75 \%$ of results worse \\
\hline Efficiency & 1,80 & Good & In the range of the $10 \%$ best results \\
\hline Dependability & 1,39 & Above Average & $25 \%$ of results better $50 \%$ of results worse \\
\hline Stimulation & 1,30 & Above Average & $25 \%$ of results better, $50 \%$ of results worse \\
\hline Novelty & 0,91 & Above Average & $25 \%$ of results better, $50 \%$ of results worse \\
\hline
\end{tabular}

Gambar 9. Hasil Set Data Benchmark. 
Gambar 9 merupakan hasil perbandingan set data benchmark dimana nilai dari skala kebaruan mendapat nilai paling rendah (dapat dilihat pada gambar 9 bagian mean) maka dari itu skala kebaruan perlu diperbaiki lagi dari sisi User Experience.

\section{KESIMPULAN}

Hasil analisis user dari proses UEQ mempengaruhi kepuasan pengguna pada saat menggunakan sistem. Pada rata-rata impresi skala kejelasan mendapatkan nilai yang tinggi dan skala kebaruan masih berada dibawah skala lainnya. Kemudian untuk data set benchmark sebagai perbandingan data 246 dari set benchmark UEQ pada skala efisiensi mendapatkan nilai tertinggi dan skala kebaruan mendapat nilai dibawah skala lainnya. Pada level User Experience daya Tarik dan efisiensi mendapatkan nilai Good (baik), pada skala kejelasan, ketepatan, stimulasi, dan kebaruan mendapatkan nilai Above Average (diatas rata- rata).

\section{DAFTAR PUSTAKA}

Adinegoro, A. L. T., Rokhmawati, R. I., \& Az-Zahra, H. M. (2018). Analisis Pengalaman Pengguna pada Website E-commerce Dengan Menggunakan Usability Testing dan User Experience Questionnaire (UEQ) (Studi pada Lazada.co.id, Blibli.com dan JD. id). Jurnal Pengembangan Teknologi Informasi Dan Ilmu Komputer (J-PTIIK) Universitas Brawijaya, 2(11), 5862-5870.

Febrianto, W. A., Putra, W. H. N., \& Perdanakusuma, A. R. (2019). Analisis Pengalaman Pengguna Aplikasi Sistem Informasi Puskesmas Paperless menggunakan Metode Usability Testing dan User Experience Questionnaire (UEQ) (Studi Kasus : Puskesmas Tarik Kabupaten Sidoarjo). Jurnal Pengembangan Teknologi Informasi Dan Ilmu Komputer, 3(6), 6099-6106.

Fitranda, F., Az-zahra, H. M., \& Herlambang, A. D. (2019). Evaluasi User Experience pada Kahoot dan Socrative menggunakan Metode User Experience Questionnaire (UEQ) (Studi pada SMKN 3 Malang). Jurnal Pengembangan Teknologi Informasi Dan Ilmu Komputer, 3(11), 10701-10704.

Halim, F., Handoko, \& Marpaung, S. H. (2020). Penilaian User Experience Fiori Bussim Menggunakan User Experience Questionaire (UEQ) Dan Pengaruhnya Terhadap. SEBATIK, 24(1), 102-112.

Izabal, S. V., Aknuranda, I., \& Az-zahra, H. M. (2018). Evaluasi dan Perbaikan User Experience Menggunakan User Experience Questionnaire
(UEQ) dan Focus Group Discussion (FGD) pada Situs Web FILKOM Apps Mahasiswa Fakultas Ilmu Komputer Universitas Brawijaya. Jurnal Pengembangan Teknologi Informasi Dan Ilmu Komputer (J-PTIIK) Universitas Brawijaya, 2(9), 3224-3232.

Septa, F., \& Umar, R. (2019). Analisis Kepuasan Pengguna Sistem Informasi E-Government Menggunakan Metode Webqual 4.0 (Studi Kasus: Website Simsarpras Kementrian Agama). METHOMIKA: Jurnal Manajemen Informatika Dan Komputerisasi Akuntansi, 3(2), 127-135.

Suastini, N. K., Lanang, I. G., \& Satwika, I. P. (2018). Analisis Pengalaman Pengguna Pada Website Distro Management System (Dimans). Jurnal Ilmiah Teknik Informatika Dan Sistem Informasi, 7(3), 135-144. Retrieved from http://ojs.stmikbanjarbaru.ac.id/index.php/jutisi/article/view/30 $0 / 284$

Umar, R., Sarjimin, S., Nugroho, A. S., Dito, A., \& Gunawan, I. (2020). Perancangan Sistem Informasi Keuangan Berbasis Web Multi User Dengan UML. Jurnal Algoritma, 17(2), 204211. https://doi.org/10.33364/algoritma/v.172.204

Umar, R., Siswanto, A., Abe, T., Lestari, T., Dzakwan, M. S., \& N, M. I. (2020). Sistem Informasi Laboratorium Klinik Berbasis Client Server. Jurnal Sains Komputer \& Informatika (J-SAKTI), 4(2), 229-235.

Widhiani, D. A. P. A., Arthana, I. K. R., \& Pradnyana, I. M. A. (2018). Analisa User Experience Pada Sistem Informasi Akademik Universitas Pendidikan Ganesha Ditinjau dari Pengguna Mahasiswa. Jurnal Pendidikan Teknologi Dan Kejuruan, 15(1), 92-102. https://doi.org/10.23887/jptkundiksha.v15i1.13048

Wulandari, I. R., \& Farida, L. D. (2018). Pengukuran User Experience Pada E-Learning Di Lingkungan Universitas Menggunakan User Experience Questionnaire (UEQ). Jurnal Mantik Penusa, 2(2), 146-151. 